\begin{abstract}
Evans J, Mackison D, Swanson V, Donnan PT, Emslie-Smith AM \& Lawton J (2013) Self-monitoring among non-insulin treated patients with type 2 diabetes mellitus: Patients' behavioural responses to readings and associations with glycaemic control, Diabetes Research and Clinical Practice, 100 (2), pp. 235-242.
\end{abstract}

This is the peer reviewed version of this article

NOTICE: this is the author's version of a work that was accepted for publication in Diabetes Research and Clinical Practice. Changes resulting from the publishing process, such as peer review, editing, corrections, structural formatting, and other quality control mechanisms may not be reflected in this document. Changes may have been made to this work since it was submitted for publication. A definitive version was subsequently published in Diabetes Research and Clinical Practice, [VOL 100, ISS 2 (2013)] DOI: http://dx.doi.org/10.1016/j.diabres.2013.03.005 


\title{
Self-monitoring among non-insulin treated patients with type 2 diabetes mellitus: Patients' behavioural responses to readings and associations with glycaemic control
}

\author{
Josie MM Evans $\mathrm{PhD}^{1}$, Senior Lecturer in Public Health \\ Dionne Mackison $\mathrm{PhD}^{1}$, Research Fellow \\ Vivien Swanson $\mathrm{PhD}^{2}$, Senior Lecturer \\ Peter T Donnan $\mathrm{PhD}^{3}$, Professor of Epidemiology and Biostatistics \\ Alistair Emslie-Smith $\mathrm{MD}^{4}$, General Practitioner \\ Julia Lawton $\mathrm{PhD}^{5}$, Professor of Health and Social Science
}

\footnotetext{
${ }^{1}$ School of Nursing, Midwifery and Health, University of Stirling, Scotland, UK

${ }^{1}$ School of Natural Sciences, University of Stirling, Scotland, UK

${ }^{3}$ Dundee Epidemiology and Biostatistics Unit, Division of Population Health Sciences,

Medical Research Institute, University of Dundee, Scotland, UK

${ }^{4}$ The Mill Practice, Dundee, Scotland, UK

${ }^{5}$ Centre for Population Health Sciences, University of Edinburgh, Scotland, UK
}

\section{Correspondence to:}

Dr Josie MM Evans PhD

School of Nursing, Midwifery and Health

University of Stirling

Stirling

Scotland

UK

FK9 4LA

Tel: 01786-466352

Fax: 01786-466333

E mail: josie.evans@stir.ac.uk

No. of Tables: 4

Word count: 3,394

Abstract word count: 207

Running title: Self-monitoring in type 2 diabetes mellitus

Funding: This study was funded by the Chief Scientist Office, Scotland (reference

$\mathrm{CZH} / 4 / 483$ ). 


\section{STRUCTURED ABSTRACT}

Aim: To investigate self-monitoring of blood glucose (SMBG) behaviour among noninsulin treated patients with type 2 diabetes mellitus, and to evaluate associations with glycaemic control. Methods: Eligible patients in 23 GP practices in Tayside, Scotland, were identified (18-75 years, no insulin treatment, SMBG reagent strips dispensed in 2009). Consenting patients were administered questionnaires addressing SMBG behavior: these primary data were record-linked to clinical data (including HbA1c) from a validated population-based diabetes clinical information system, then anonymised. Results: Among 629 eligible patients, 207 were interviewed and analysed. Mean SMBG reagent strips dispensed in 12 months was 268. Eighty (38.8\%) patients took no action in response to perceived high test results, or simply checked later. Most (61.3\%) did not know what action to take. $126(61.2 \%)$ patients took action, including dietary $(\mathrm{n}=101)$, physical activity $(\mathrm{n}=12)$ or medication $(\mathrm{n}=10)$ changes, or making a HCP appointment $(\mathrm{n}=12)$. High score on a Diabetes Knowledge Test was a statistically significant predictor of taking action (odds ratio: 2.07). However, neither taking action nor increased SMBG frequency were associated with improved glycaemic control. Conclusions: Responding to SMBG test results and increased testing frequency were not associated with improved glycaemic control in the short-term. There is a lack of knowledge surrounding SMBG in non-insulin treated patients.

KEYWORDS: Type 2 diabetes, Blood Glucose Monitoring, Glycaemic control 


\section{INTRODUCTION}

The value of self-monitoring of blood glucose (SMBG) in insulin-treated patients with diabetes mellitus is well established ${ }^{1,2}$, but its utility in non-insulin treated patients remains controversial. Despite this, SMBG is becoming increasingly common ${ }^{3}$ (and $\operatorname{costly}^{4}$ ) among this group of patients. Proponents of SMBG argue that it can provide 'real time' information about hyperglycemic or hypoglycemic excursions, and thus help patients make day-to-day behavioural choices to help keep blood glucose levels within clinically recommended target ranges ${ }^{5}$. However, there is limited empirical evidence of clinical benefit. A recent report from an NHS Diabetes Working Group, that included a systematic review of 26 RCTs and 36 observational studies, concluded that SMBG is associated with only minimal improvements in glycaemic control, and is unlikely to be effective in non-insulin treated patients ${ }^{6}$. SMBG is no longer routinely recommended to patients who do not use insulin ${ }^{6,7}$.

What is almost universally lacking from studies on monitoring is consideration of how (and why) patients use self-monitoring as a self-management tool. Whether an appropriate response, or indeed any response at all, is made to high or low blood glucose readings is the key to understanding whether self-monitoring can be clinically effective ${ }^{8}$. Many insulin-using patients adjust insulin doses in response to readings, but non-insulin using patients cannot do this. In a large recent survey in the United States, $56 \%$ of patients took no action at all in response to out-of-range $\mathrm{SMBG}$ readings ${ }^{3}$. Such patients are unlikely to derive clinical benefit from SMBG. Heller et al (2010) have identified a lack of education among patients in how to interpret and use data from $\mathrm{SMBG}^{6}$. 
However, we raise the question as to whether there may be some groups of patients with type 2 diabetes mellitus who monitor regularly, have received suitable education and make appropriate responses to high and low readings, for whom a clinical benefit might be identifiable. In this cross-sectional study in Tayside, Scotland, we therefore administered questionnaires to patients with type 2 diabetes mellitus who had no record of insulin use to investigate their SMBG behaviours in detail. We then linked the information obtained to clinical data from a population-based diabetes clinical information system. We were thus able to evaluate the associations between SMBG behaviour (and other clinical and demographic variables) and glycaemic control. 


\section{MATERIALS AND METHODS}

This study was carried out in the population of Tayside, Scotland, UK (approx. 400,000 people). All 74 General Practices in the area were sent an invitation to assist with the study, of which 23 agreed. We used the SCI-DC diabetes clinical information system to identify patients for the study. SCI-DC (Scottish Care Information - Diabetes Collaboration) is a validated population-based diabetes information system in Tayside, Scotland, compiled by record-linking several independent data sources (formerly known as DARTS: Diabetes Audit and Research in Tayside, Scotland) ${ }^{9}$. Eligible patients within each participating GP practice were: aged 18 to 75 years, diagnosed with type 2 diabetes mellitus, had no electronic record of any prescription dispensed for insulin, had received at least one prescription for reagent strips for SMBG in 2009 (or in 2010 if they were newly diagnosed). Anonymised data only were analysed for these patients.

Permission was then requested from the GP of each individual patient to collect further data. Patients were sent an invitation letter from their GP, an information sheet and an opt-out form. Those who did not return the opt-out form were contacted by a Research Fellow, and if they consented, were interviewed by the Research Fellow between June 2010 and September 2011.

The Research Fellow administered a set of questionnaires to the patients in their own homes, which took around one hour. The main questionnaires addressed SMBG behaviours; including timing and frequency of monitoring, understanding of blood glucose readings and actions taken in response to readings. Patients were asked to think 
of a time when they experienced a high or low blood glucose reading that caused them concern, and whether they then made any behavioural response. The questionnaire was developed in the light of findings from earlier qualitative work with non-insulin treated patients $^{10,11}$, and also with the advice of a lay person with diabetes mellitus. It was subsequently piloted and refined among eight patients in one pilot practice. Other validated questionnaires included the MDRTC Diabetes Knowledge Test ${ }^{12}$, the Diabetes Summary of Self Care Activities ${ }^{13}$ and the Brief Illness Perceptions questionnaire ${ }^{14}$. Primary data collected by questionnaire were record-linked to patients' clinical information on the SCI-DC clinical information system, then anonymised prior to analysis. Data were also assembled for patients who were not interviewed.

Every patient was assigned an index date. This was either the date that they were interviewed, or if they were not interviewed, the date that the first patient in their practice was interviewed. To derive an objective measure of SMBG frequency, the number of reagent strips that had been dispensed in the 12 month period prior to the index date was calculated for every eligible patient in the study. This number was derived from total numbers of packs dispensed recorded on the prescription form. The most recent HbA1c value in the 6 month period prior to the index date of every study patient was also identified from SCI-DC.

We investigated whether patients took action in response to test results. Patients were asked whether they took action in response to 'a [high] or [low] reading that has caused you concern' and categorized according to whether or not they took action. They were 
also asked the reason for this. Possible predictors of action were then evaluated in a univariate logistic regression analysis, and included age, sex, SIMD deprivation quintile (a postcode measure of multiple material and social deprivation ${ }^{15}$ ), self-reported level of education, diabetes duration (as recorded on SCI-DC), diabetes knowledge (measured by the Diabetes Knowledge Test) and treatment (defined according to electronic records of prescriptions dispensed). Covariates that were statistically significant in the univariate analysis $(\mathrm{p} \leq 0.05)$ were then entered into a multivariate regression model.

Patients with poor glycaemic control $(\mathrm{HbA} 1 \mathrm{c}>=8.0 \%$ or $64 \mathrm{mmol} / \mathrm{mol})$ were identified and poor control was defined as the dependent variable in a binary logistic regression for the patients who were interviewed. In univariate analyses, we assessed whether the covariates defined previously were predictors of poor control; we also added in SMBG frequency (measured by the numbers of reagent strips dispensed for SMBG), selfreported SMBG frequency, and whether or not the patient took action in response to test readings. As previously, covariates that were statistically significant $(p \leq 0.05)$ in the univariate analysis were entered into a multivariate regression model. This process was then repeated for the entire sample of interviewed and non-interviewed patients.

This study had ethical approval from the Tayside Committee for Medical Research Ethics (reference 09/S1401/48). The data of those patients who opted-out of being interviewed were analysed anonymously. 


\section{RESULTS}

There were 629 eligible patients in 23 GP practices, of which GPs withheld permission to approach 61. Among the remaining patients, 111 patients actively opted-out and 225 declined at a later stage or could not be contacted. 232 interviews were therefore completed, of which 207 were analysed ( 25 patients who had already been advised by their GPs to discontinue monitoring were excluded). The characteristics of the 207 interviewed patients were compared with those of non-interviewed patients and were generally similar, with just over half the interviewed sample male (58\%), with a mean age of 63 years (range 36-76 years), and mean diabetes duration of 97 months, compared to 56\%, 60 years and 89 months respectively (Table 1). Nearly one third of interviewed patients had had diabetes mellitus for more than 10 years, with few (8\%) diagnosed within the last two years. The mean number of strips dispensed in a 12 month period for patients who received at least some strips was 268 for the 207 interviewed patients and 232 for non-interviewed patients, with respective medians of 200 and 150. Mean HbA1c was $7.45 \%$ and $7.77 \%$ respectively; this difference was statistically significant.

206 of the 207 interviewed patients reported having experienced a high blood glucose reading, in contrast to only 109 who had experienced a low blood glucose reading. Among the latter, almost all reported that they had made a dietary change in response (e.g. consuming a biscuit or sugary drink). The 206 patients were subsequently categorised according to how they responded to high blood glucose readings:

No Action: 80 (38.8\%) patients reported either taking no action $(\mathrm{n}=59)$ or simply checking their blood glucose levels again later $(n=21)$. The reason given for this by 49 
$(61.3 \%)$ patients was that they did not know what action to take. Among the remaining patients, 22 patients were either not concerned / just accepted high readings, eight found that taking action made no difference and one patient found it too difficult.

Some Action: $126(61.2 \%)$ patients took some form of action. These (not mutually exclusive) actions included making changes to diet - predominately cutting down on fats and sugary foods for a few days - $(n=101)$, increasing physical activity $(n=12)$, making changes to medication $(n=10)$, or making an appointment with a health care practitioner $(n=12)$.

In a univariate regression analysis, females were more likely to report taking action than males, although this was not statistically significant in the multivariate analysis. However, the most important independent predictor of action appeared to be diabetes knowledge. Patients who scored highly in a Diabetes Knowledge Test were twice as likely to take action as those who scored less well.

We investigated predictors of poor control in the 207 patients who were interviewed (Table 3) and again in the entire sample of 629 patients (Table 4). Among patients for whom HbA1c was available, $28.0 \%$ of interviewed patients had $\mathrm{HbAlc} \geq 8$; the figure was $32.6 \%$ in the entire sample. Table 3 shows that older patients were less likely to have poor control, but patients treated with sulphonylureas and metformin in combination, or with injections of exenatide or liraglutide, were more likely to have poor control than patients treated with metformin only. However, SMBG frequency, whether measured by the number of reagent strips dispensed or by self-report, was not associated 
with glycaemic control; neither was there any discernible associaton between glycaemic control and diabetes knowledge, education or whether a patient took action in response to high results.

In the larger sample, the statistically significant associations with poor glycaemic control, for increasing age, treatment with sulphonylureas and metformin in combination, and with injections, were confirmed (Table 4). Daily SMBG (measured by strips dispensed) was associated with poor control in the univariate analysis, but this was no longer evident in the multivariate model. 


\section{DISCUSSION}

This study shows that SMBG frequency among patients with type 2 diabetes mellitus in Scotland who are not treated with insulin is relatively high, with the mean number of reagent strips dispensed sufficient for monitoring most days. The study also suggests that there is a lack of knowledge surrounding SMBG among non insulin-treated patients, with more than one-third of a sample of 207 of such patients reporting taking no action in response to SMBG results. Over one half of those who reported taking no action stated that this was because they did not know what (or how) to do. However, a minority of these patients did state that they checked their blood glucose levels later if they had a high blood glucose reading. Although this might be considered an appropriate response, these patients were categorized as taking no action for subsequent analyses.

In a regression model, there was an association between an objective measure of diabetes knowledge and whether a patient reported taking action. Patients who scored highly on knowledge were twice as likely to take action as those who scored less well. Although we cannot discount the possibility of social desirability bias (the tendency of respondents to distort the self-reporting of behaviour in a favourable direction, with more knowledgeable patients aware that reporting taking action in response to test results supports the expectations of health care professionals ${ }^{16}$ ), the consistent strands of evidence do suggest that a lack of knowledge is a key factor in whether a patient responds to test results. This lack of knowledge may relate to the implications of high readings, the most effective way to reduce SMBG readings or how to make the required behavioural changes; and may be because patients do not receive adequate education surrounding SMBG. 
In regression analyses, we also evaluated possible predictors of poor glycaemic control. Older patients were less likely to have poor glycaemic control in both analyses, and this has been reported in other studies ${ }^{17,18}$. We also identified treatment with a combination of metformin and sulphonylureas, and treatment with injections of liraglutide and exenatide, as being associated with poor glycaemic control. This is likely to be due to patients with poor glycaemic control being channeled into more aggressive treatment.

In terms of SMBG behavior, patients who reported taking action in response to test results were no less likely to have poor glycaemic control than those who did not make any response. There are several possible explanations for this lack of association. First, it may be that patients who report taking action do not actually take action (as discussed above). Second, it may be that the actions that patients take are ineffective. The most common 'action' was making short term changes to diet, but such reactive behavior may well have no discernible effect on long-term control. Third, we asked patients whether they took action in response to a 'reading that has caused you concern'. However, we did not specifically ask patients how high their readings needed to be before they were 'concerned', so it is difficult to determine whether they took action at the appropriate time or at an appropriate blood glucose level. However, regardless of the explanation, actions that patients are taking - at whatever time - are not associated with improved glycaemic control in the short-term. These results contrast to those of from a recent trial where non-insulin-using patients who adhered to a structured SMBG protocol did have improved glycaemic control ${ }^{19}$. However, this was a relatively intensive intervention 
whereby patients and clinicians collaboratively evaluated patterns of SMBG results over a 3-day period to plan lifestyle and medication changes; very different to observed practice in our study.

Although there was no association between self-reported SMBG frequency and glycaemic control, daily monitoring as measured objectively by numbers of reagent strips dispensed, was associated with poor control. While this could be a reflection of patients with poor control motivated to monitor more frequently, the association was no longer evident after adjusting for treatment. It is important to recognize the potential confounding effect of treatment in any future cross-sectional, observational studies in this area.

We found no associations between deprivation (in either analysis) and self-reported education level and poor glycaemic control, in contrast to other studies ${ }^{17,18}$. This is perhaps surprising given the well-established associations between disadvantage and poor outcomes in diabetes ${ }^{20}$. However, it may be that the measures that we used were not sensitive enough to discriminate sufficiently between patients, therefore diluting any effects that were present.

The study was carried out with a self-selected sample of patients who agreed to be interviewed. We did not specifically ask why some patients did not wish to be interviewed, but the demographic characteristics of the interviewed patients were similar to those of the total population. Despite this, we cannot exclude the possibility that their 
SMBG behaviour was different. The mean number of strips dispensed to them was indeed slightly higher. They also had lower HbAlc, and could perhaps have been more motivated, interested in and positive about SMBG. If this is the case, however, then the lack of knowledge identified among these possibly more motivated patients is even more concerning. Also, it is noteworthy that other associations that were identified in the smaller self-selected group for glycaemic control were confirmed in the entire sample of non-selected patients.

Data for the study came from self-report measures and from electronic records of clinical data from SCI-DC. All patients were interviewed by the same Research Fellow who adhered to a pre-defined protocol for administering the questionnaires. While these questionnaires were either existing, validated measures, or ones that had been developed and tested with a lay service user with diabetes mellitus and then refined in a pilot study, we can not be completely certain that patients gave accurate responses to questions asked. Further studies conducted on a larger scale may therefore benefit from a more in-depth assessment of content validity to ensure items are collecting responses as intended. In contrast, SCI-DC is a validated population-based clinical information system that has been widely used in epidemiological research, and we are confident in data derived from it. However, in terms of reagent strips dispensed for SMBG, while we know that patients were dispensed the strips, we cannot be sure that they actually used them. They may also have received strips from other sources. We also identified 43 interviewed patients who had received no reagent strips in the 12 month period prior to their index date; although receiving strips in 2009 was an eligibility criterion, as was self-reported current 
monitoring. It is possible that they had stocks of reagent strips dispensed previously, and/or they were monitoring very infrequently, and indeed a similar number self-reported infrequent monitoring. In general though, the numbers of strips dispensed were higher than those reported in earlier studies in Tayside ${ }^{21}$, suggesting that most of the interviewed patients received enough strips to monitor at least 3-4 times per week, and tallying fairly well with self-report frequency.

This was a cross-sectional study in that all the data were collected from interviewed patients at the same point in time. This can mean that it is difficult to determine the order in which particular events or outcomes occurred. However, HbA1c values were electronically recorded and we identified the $\mathrm{HbA} 1 \mathrm{c}$ measure nearest in time over a 6month period prior to the date of the patient's interview. This was in order to relate the HbA1c measure in time to the SMBG practices that patients were describing.

We believe that the associations we identified in this study are valid. However, the number of interviewed patients was relatively small, so it is possible that the study was not sufficiently powered to detect some associations which were relatively large. For example, with a sample size of 207 , divided equally between two groups, the study had $80 \%$ power to detect differences in categorical variables of around $14 \%$. A larger sample would be needed to detect smaller differences. Despite this limitation, we have gone further than other studies in attempting to characterize how patients monitor and respond to test results. Despite this, the study still gives a strong indication that SMBG, as currently practised in Tayside, is not associated with improved glycaemic control in the 
short-term, and highlights the lack of knowledge surrounding SMBG in non-insulin treated patients with type 2 diabetes mellitus. It is also important to establish whether these results would be replicated in other regions and countries.

The American Association of Diabetes Educators has recently made a call for all patients with diabetes to receive standardised and tailored education on SMBG, advocating that 'safe and appropriate blood glucose monitoring methods need to be taught including selfmanagement skills that incorporate and utilize the data obtained from blood glucose monitoring for an individualized program of self care ${ }^{, 22}$. This should not only include education on the mechanics of operating meters, how often to test, and how to record the results, but also what to do with blood glucose results, target blood glucose goals, and when to test. Similarly, one of the key recommendations from NHS Diabetes $(2010)^{6}$ is that 'SMBG should only be used within a care package, accompanied by structured education which should include clear instructions as to the place of monitoring and how results can be used to reinforce lifestyle change, adjust therapy or alert health professionals'. The results from our study strongly support these recommendations. 


\section{ACKNOWLEDGEMENTS}

We thank the patients who agreed to be interviewed for this project and the General Practitioners in Tayside, Scotland, who facilitated contact with them. We also thank our lay user representative who was involved at all stages of the project and the Health

Informatics Centre, University of Dundee, for data provision. Dr Josie Evans is the guarantor of the study.

\section{DECLARATION OF COMPETING INTERESTS}

No Conflicts of Interest have been declared by the authors. 


\section{REFERENCES}

1. Scottish Intercollegiate Guidelines Network (SIGN) (2010). Management of diabetes. A national clinical guideline. 116.

2. Reynolds RM, Webb DJ. Recommendations and conclusions from a minisymposium on self-blood glucose monitoring. $J R$ Coll Physicians Edinb 2006;36:155-8.

3. Polonsky WH, Fisher L, Hessler D, Edelman SV. A survey of blood glucose monitoring in patients with type 2 diabetes: are recommendations from health care professionals being followed? Current Medical Research \& Opinion 2011; 27(S3): 31-37.

4. Reynolds RM, Strachan MWJ. Home blood glucose monitoring in type 2 diabetes. Br Med J 2004;329:754-755.

5. Boutati EI, Raptis SA. Self-monitoring of blood glucose as part of the integral care of type 2 diabetes. Diabetes Care 2009; Suppl 2:S205-10.

6. Heller S et al. A report prepared by an NHS Diabetes Working Group. Self monitoring of blood glucose in non-insulin-treated type 2 diabetes. NHS Diabetes, 2010.

7. Clar C, Barnard K, Cummins E, Royle P, Waugh N. Self-monitoring of blood glucose in type 2 diabetes: systematic review. Health Technol Assess 2010; 14.

8. Ipp E, Aquino RL, Christenson P. Point: Self-monitoring of blood glucose in type 2 diabetes not receiving insulin. The sanguine approach. Diabetes Care 2005; 28:1528-1530.

9. Morris AD, Boyle DIR, MacAlpine R et al. The diabetes audit and research in Tayside, Scotland (DARTS) study: electronic record-linkage to create a diabetes register. Br Med J 1997; 315:5245-28. 
10. Peel E, Douglas M, Lawton J. Self-monitoring of blood glucose in type 2 diabetes: Longitudinal qualitative study of patients' perspectives. $\mathrm{Br}$ Med J 2007; doi:10.1136/bmj.39302.444572.DE

11. Peel E, Parry O, Douglas M, Lawton J. Blood glucose self-monitoring in noninsulin treated type 2 diabetes: qualitative study of patients' perspectives. British Journal of General Practice 2004, 54: 183-188.

12. Fitzgerald JT, Anderson RM, Funnell MM, Hiss RG, Hess GE, Davis WK, Barr PA. The reliability and validity of a brief diabetes knowledge test.

13. Toobert DJ, Hampson SE, Glasgow RE. The summary of diabetes self-care activities measure: results from 7 studies and a revised scale. Diabetes Care 2000; 23:943-950.

14. Broadbent E, Petrie KJ, Main J, Weinman J. The brief illness perceptions questionnaire. J Psychosomatic Res 2006; 60:631-637.

15. Using the Scottish Index of Multiple Deprivation 2006: Guidance leaflet. http://www.scotland.gov.uk/Publications/2006/10/13142841/1.

16. van de Mortel TF. Faking it: social desirability response bias in self-report research. Australian Journal of Advanced Nursing 2005; 25:40-48.

17. Benoit SR, Fleming R, Philis-Tsimikas A, Ming J. Predictors of glycemic control among patients with Type 2 diabetes: A longitudinal study. BMC Public Health $2005 ; 5: 36$.

18. Goudswaard AN, Stolk RP, Zuithoff P, Rutten GEHM. Patient characteristics do not predict poor glycemic control in type 2 diabetes patients treated in primary care. Eur J Epidemiol 2004; 19:541-545.

19. Polonsky WH, Fisher L, Schikman CH, Hinnen DA, Parkin CG, Jelsovsky Z, Wagner RS. Structured self monitoring of blood glucose significantly reduces 
A1C levels in poorly controlled, noninsulin- treated type 2 diabetes. Results from the Structured Testing Program Study. Diabetes Care; 2011:34:262-267.

20. Brown AF, Ettner SL, Piette J, Weinberger M, Gregg E, Shapiro MF, Karter AJ, Safford M, Waitzfelder B, Prata PA, Beckles GL: Socioeconomic position and health among persons with diabetes mellitus: a conceptual framework and review of the literature. Epidemiol Rev 26:63-77, 2004

21. Evans JMM, Mackison D, Emslie-Smith A, Lawton J. Self-monitoring of blood glucose in type 2 diabetes: Cross-sectional analyses in 1993, 1999 and 2009. Diabetic Medicine 2012; 29:1-4.

22. American Association of Diabetes Educators. AADE Position Statement: Selfmonitoring of blood glucose. Diabetes Care 2009; 1:s17-19. 
Table 1: Characteristics of study population, and those who were interviewed

\begin{tabular}{|c|c|c|c|}
\hline & $\begin{array}{l}629 \text { patients } \\
\text { identified by HIC as } \\
\text { eligible for the study }\end{array}$ & $\begin{array}{l}207 \text { interviewed } \\
\text { patients who still } \\
\text { self-monitored }\end{array}$ & $\begin{array}{l}422 \text { non-interviewed } \\
\text { patients (or who no } \\
\text { longer monitored) }\end{array}$ \\
\hline & No (\%) & No (\%) & $\mathrm{No}(\%)$ \\
\hline \multicolumn{4}{|l|}{ Sex } \\
\hline Males & $355(56.4)$ & $119(57.5)$ & $236(55.9)$ \\
\hline Females & $274(43.6)$ & $88(42.5)$ & $186(44.1)$ \\
\hline \multicolumn{4}{|l|}{ Age } \\
\hline$<50$ years & $98(15.6)$ & $20(9.7)$ & $78(18.5)$ \\
\hline $50-59$ years & $154(24.5)$ & $43(20.8)$ & $111(26.3)$ \\
\hline $60-69$ years & $234(37.2)$ & $85(41.1)$ & $149(35.3)$ \\
\hline $70-76$ years & $143(22.7)$ & $59(28.5)$ & 84 (19.9) \\
\hline Mean age & 61 years (SD 10) & 63 years (SD 9) & 60 years (SD 10) \\
\hline \multicolumn{4}{|l|}{ Diabetes duration } \\
\hline Less than 2 years & $80(12.7)$ & $17(8.2)$ & $63(14.9)$ \\
\hline $2-5$ years & $187(29.7)$ & $67(32.4)$ & $120(28.4)$ \\
\hline $6-9$ years & $201(32.0)$ & $63(30.4)$ & $138(32.7)$ \\
\hline 10 years + & $161(25.6)$ & $60(29.0)$ & $101(23.9)$ \\
\hline Mean duration (months) & 95 months (SD 67) & 97 months (SD 66) & 89 months (SD 68) \\
\hline \multicolumn{4}{|l|}{ SIMD Quintile ${ }^{I}$} \\
\hline 1 (most deprived) & $88(14.0)$ & 24 (11.6) & $64(15.2)$ \\
\hline 2 & $110(17.5)$ & $37(17.9)$ & $73(17.3)$ \\
\hline 3 & $119(18.9)$ & $33(15.9)$ & $86(20.4)$ \\
\hline 4 & $189(30.0)$ & $72(34.8)$ & $117(27.7)$ \\
\hline 5 (least deprived) & $107(17.0)$ & $38(18.4)$ & $69(16.4)$ \\
\hline \multicolumn{4}{|l|}{ Treatment } \\
\hline Metformin $^{2}$ & $182(28.9)$ & $56(27.1)$ & $126(29.9)$ \\
\hline Sulphonylurea $^{3}$ & $55(8.7)$ & $17(8.2)$ & $38(9.0)$ \\
\hline $\begin{array}{l}\text { Metformin and } \\
\text { sulphonylurea }\end{array}$ & $272(43.2)$ & $92(44.4)$ & $180(42.7)$ \\
\hline $\begin{array}{l}\text { Injections of exenatide } \\
\text { or liraglutide }\end{array}$ & $64(10.2)$ & $26(12.6)$ & $38(9.0)$ \\
\hline Diet / lifestyle only & $53(8.4)$ & $15(7.2)$ & $38(9.0)$ \\
\hline \multicolumn{4}{|l|}{$\begin{array}{l}\text { Reagent strips } \\
\text { dispensed }^{4}\end{array}$} \\
\hline $\begin{array}{l}\text { Number who received } \\
\text { any strips in } 12 \text { month } \\
\text { prior to interview }\end{array}$ & $447(74.8)$ & $162(78.6)$ & $285(72.9)$ \\
\hline Mean strips dispensed & 245 (SD 222) & 268 (SD 222) & $232(221)$ \\
\hline Median strips dispensed & 200 & 200 & 150 \\
\hline \multicolumn{4}{|l|}{ HbA1C data ${ }^{5}$} \\
\hline Mean $\mathrm{HbA} 1 \mathrm{c}^{6}$ & 7.66 (SD 1.6) & 7.45 (SD 1.4) & 7.77 (SD 1.7) \\
\hline Median HbA1c & 7.30 & 7.10 & 7.40 \\
\hline
\end{tabular}


${ }^{1}$ SIMD Scotland Quintile (SIMD - Scottish index of multiple deprivation). Identified based on patient's full postcode at the date of interview; available for 613 of 629 patients and 204 of 207 patients respectively.

${ }^{2}$ Or combined with pioglitazone, rosiglitazone, sitagliptin

${ }^{3}$ Or combined with pioglitazone, rosiglitazone, sitagliptin, saxagliptin

${ }^{4}$ Only patients with at least 12 months diabetes duration included (597,205 and 391 patients respectively).

${ }^{5}$ Most recent $\mathrm{HbA} 1 \mathrm{c}$ value in the 6 months prior to index date (excluding outlying values $>20$ )

${ }^{6} \mathrm{An}$ independent samples $\mathrm{t}$ test indicated that the difference in mean HbA1c between interviewed and noninterviewed patients was statistically significant $(\mathrm{p}=0.03)$ 
Table 2: Results of binary logistic regression for whether a patient reported taking action in response to test results $(n=207)$

\begin{tabular}{|c|c|c|c|c|c|c|}
\hline & Total & $\begin{array}{l}\text { No (\%) } \\
\text { that took } \\
\text { action }\end{array}$ & $\begin{array}{l}\text { Unadjusted odds } \\
\text { ratio }(95 \% \mathrm{CI})\end{array}$ & $\begin{array}{l}\mathrm{p} \\
\text { value }\end{array}$ & $\begin{array}{l}\text { Adjusted odds } \\
\text { ratio }(95 \% \mathrm{CI})\end{array}$ & $\begin{array}{l}\mathrm{p} \\
\text { value }\end{array}$ \\
\hline \multicolumn{7}{|l|}{ Sex } \\
\hline Males & 119 & $67(56.3)$ & 1.00 & & 1.00 & \\
\hline Females & 88 & $59(67.0)$ & $1.64(0.92-2.91)$ & 0.09 & $1.46(0.80-2.67)$ & 0.22 \\
\hline \multicolumn{7}{|l|}{ Age } \\
\hline$<50$ & 20 & $14(70.0)$ & 1.00 & & - & - \\
\hline $50-59$ & 43 & $31(72.1)$ & $1.11(0.35-3.55)$ & 0.86 & - & - \\
\hline $60-69$ & 85 & $46(54.1)$ & $0.52(0.18-1.48)$ & 0.22 & - & - \\
\hline$>70$ & 59 & $35(59.3)$ & $0.63(0.21-1.86)$ & 0.40 & - & - \\
\hline \multicolumn{7}{|l|}{ SIMD } \\
\hline $\begin{array}{l}1 \text { (most } \\
\text { deprived) }\end{array}$ & 24 & $14(58.3)$ & 1.00 & & - & - \\
\hline 2 & 37 & $27(73.0)$ & $2.14(0.71-6.49)$ & 0.18 & - & - \\
\hline 3 & 33 & $17(51.5)$ & $0.76(0.26-2.19)$ & 0.61 & - & - \\
\hline 4 & 72 & $47(65.3)$ & $1.34(0.52-3.46)$ & 0.54 & - & - \\
\hline $\begin{array}{l}5 \text { (least } \\
\text { deprived) }\end{array}$ & 38 & $20(52.6)$ & $0.79(0.28-2.23)$ & 0.66 & - & \\
\hline \multicolumn{7}{|c|}{ Education / qualifications } \\
\hline $\begin{array}{l}\text { None / school } \\
\text { level }\end{array}$ & 101 & $61(60.4)$ & 1.00 & & - & - \\
\hline $\begin{array}{l}\text { Post school / } \\
\text { diploma }\end{array}$ & 73 & $42(57.5)$ & $0.87(0.47-0.61)$ & 0.65 & - & - \\
\hline $\begin{array}{l}\text { Professional / } \\
\text { degree }\end{array}$ & 32 & $22(68.8)$ & $1.41(0.60-3.29)$ & 0.43 & - & - \\
\hline \multicolumn{7}{|c|}{ Diabetes Duration } \\
\hline$<2$ years & 17 & $9(52.9)$ & 1.00 & & & \\
\hline $2-5$ years & 67 & $42(62.7)$ & $1.59(0.51-4.37)$ & 0.46 & - & - \\
\hline 6-9 years & 63 & $36(57.1)$ & $1.23(0.42-3.62)$ & 0.71 & - & - \\
\hline$>10$ years & 60 & $39(65.0)$ & $1.65(0.56-4.91)$ & 0.37 & - & - \\
\hline \multicolumn{7}{|l|}{ Knowledge } \\
\hline $0-10$ & 148 & $83(56.1)$ & 1.00 & & 1.00 & \\
\hline $11-13$ & 51 & $38(74.5)$ & $2.25(1.11-4.58)$ & 0.03 & $2.07(1.00-4.26)$ & 0.05 \\
\hline \multicolumn{7}{|l|}{ Treatment } \\
\hline Metformin & 56 & $30(53.6)$ & 1.00 & & & \\
\hline Sulph & 17 & $7(41.2)$ & $0.58(0.19-1.76)$ & 0.34 & - & - \\
\hline Met / sulph & 92 & $60(65.2)$ & $1.57(0.79-3.09)$ & 0.20 & - & - \\
\hline Injections & 26 & $18(69.2)$ & $1.88(0.70-5.03)$ & 0.21 & - & - \\
\hline Diet/lifestyle & 15 & $11(73.3)$ & $2.29(0.65-8.09)$ & 0.20 & - & - \\
\hline
\end{tabular}


Table 3: Results of binary logistic regression for glycaemic control $(\mathrm{HbA1c}>=8$ as dependent variable) for 193 of 629 eligible patients who were interviewed and had an $\mathrm{HbA1c}$ value recorded

\begin{tabular}{|c|c|c|c|c|c|c|}
\hline & Total & $\begin{array}{l}\text { No }(\%) \\
\text { HbA1c } \\
>=8\end{array}$ & $\begin{array}{l}\text { Unadjusted odds } \\
\text { ratio }(95 \% \mathrm{CI})\end{array}$ & $\begin{array}{l}\mathrm{p} \\
\text { value }\end{array}$ & $\begin{array}{l}\text { Adjusted odds } \\
\text { ratio }(95 \% \mathrm{CI})\end{array}$ & $\begin{array}{l}\mathrm{p} \\
\text { value }\end{array}$ \\
\hline \multicolumn{7}{|l|}{ Sex } \\
\hline Males & 108 & $32(29.6)$ & 1.00 & & - & - \\
\hline Females & 85 & $21(24.7)$ & $0.77(0.40-1.47)$ & 0.42 & - & - \\
\hline \multicolumn{7}{|l|}{ Age } \\
\hline$<50$ & 20 & $9(45.0)$ & 1.00 & & 1.00 & \\
\hline $50-59$ & 36 & $14(38.9)$ & $0.78(0.26-2.35)$ & 0.66 & $1.19(0.35-4.09)$ & 0.78 \\
\hline $60-69$ & 79 & $20(25.3)$ & $0.41(0.15-1.15)$ & 0.09 & $0.76(0.24-2.39)$ & 0.64 \\
\hline$>70$ & 58 & $10(17.2)$ & $0.26(0.08-0.78)$ & 0.02 & $0.44(0.13-1.52)$ & 0.20 \\
\hline \multicolumn{7}{|l|}{ SIMD } \\
\hline $\begin{array}{l}1 \text { (most } \\
\text { deprived) }\end{array}$ & 22 & $5(22.7)$ & 1.00 & & - & - \\
\hline 2 & 34 & $10(29.4)$ & $1.42(0.41-4.90)$ & 0.58 & - & - \\
\hline 3 & 33 & $9(27.3)$ & $1.28(0.36-4.48)$ & 0.71 & - & - \\
\hline 4 & 66 & $22(33.3)$ & $1.70(0.55-5.21)$ & 0.35 & - & - \\
\hline $\begin{array}{l}5 \text { (least } \\
\text { deprived) }\end{array}$ & 35 & $7(20.0)$ & $0.85(0.23-3.11)$ & 0.81 & - & \\
\hline \multicolumn{7}{|c|}{ Diabetes Duration } \\
\hline$<2$ years & 13 & $2(15.4)$ & 1.00 & & - & - \\
\hline $2-5$ years & 62 & $14(22.6)$ & $1.60(0.32-8.11)$ & 0.57 & - & - \\
\hline $6-9$ years & 61 & $19(31.1)$ & $2.49(0.50-12.34)$ & 0.27 & - & - \\
\hline$>10$ years & 57 & $18(31.6)$ & $2.54(0.51-12.66)$ & 0.26 & - & - \\
\hline \multicolumn{7}{|l|}{ Treatment } \\
\hline Metformin & 52 & $9(17.3)$ & 1.00 & & 1.00 & \\
\hline Sulph & 17 & $1(5.9)$ & $0.32(0.04-2.73)$ & 0.30 & $0.44(0.05-3.91)$ & 0.46 \\
\hline Met / sulph & 86 & $27(31.4)$ & $2.22(0.95-5.21)$ & 0.07 & $2.53(1.05-6.08)$ & 0.04 \\
\hline Injections & 24 & $13(54.2)$ & $5.65(1.92-16.59)$ & 0.02 & $5.19(1.73-15.59)$ & 0.003 \\
\hline \multicolumn{7}{|l|}{ Frequency } \\
\hline No strips & 43 & $13(30.2)$ & 1.00 & & & \\
\hline $\begin{array}{l}\text { < Once per } \\
\text { week }\end{array}$ & 13 & $2(15.4)$ & $0.42(0.08-2.17)$ & 0.30 & - & - \\
\hline $\begin{array}{l}1-4 \text { times per } \\
\text { week }\end{array}$ & 65 & $17(26.2)$ & $0.82(0.35-1.92)$ & 0.64 & - & - \\
\hline $\begin{array}{l}\text { 4-7 times per } \\
\text { week }\end{array}$ & 35 & $7(20.0)$ & $0.58(0.20-1.65)$ & 0.31 & - & - \\
\hline $\begin{array}{l}\text { At least daily } \\
\text { Self- } \\
\text { reported }\end{array}$ & 35 & $12(34.3)$ & $1.20(0.46-3.13)$ & 0.70 & - & - \\
\hline
\end{tabular}




\begin{tabular}{|c|c|c|c|c|c|c|}
\hline \multicolumn{7}{|l|}{ frequency } \\
\hline $\begin{array}{l}\text { Rarely/occasi } \\
\text { onally }\end{array}$ & 42 & $11(26.2)$ & 1.00 & & - & - \\
\hline Most weeks & 26 & $9(34.6)$ & $1.49(0.52-4.31)$ & 0.46 & - & - \\
\hline Every week & 56 & $9(16.1)$ & $0.54(0.20-1.45)$ & 0.22 & - & - \\
\hline Most days & 12 & $5(41.7)$ & $2.01(0.53-7.67)$ & 0.31 & - & - \\
\hline At least daily & 57 & $19(33.3)$ & $1.41(0.58-3.40)$ & 0.45 & - & - \\
\hline \multicolumn{7}{|c|}{ Self-reported action } \\
\hline No action & 74 & $19(25.7)$ & 1.00 & & - & - \\
\hline Action & 118 & $34(28.8)$ & $1.17(0.61-2.26)$ & 0.64 & - & - \\
\hline \multicolumn{7}{|c|}{ Diabetes Knowledge } \\
\hline Low score & 135 & $37(27.4)$ & 1.00 & & - & - \\
\hline High score & 50 & $13(26.0)$ & $0.93(0.45-1.94)$ & 0.85 & - & - \\
\hline \multicolumn{7}{|l|}{ Education } \\
\hline $\begin{array}{l}\text { None/school } \\
\text { level }\end{array}$ & 79 & $21(26.6)$ & 1.00 & & - & - \\
\hline $\begin{array}{l}\text { Post school / } \\
\text { diploma }\end{array}$ & 15 & $5(33.3)$ & $1.38(0.42-4.51)$ & 0.59 & - & - \\
\hline $\begin{array}{l}\text { Professional } \\
\text { / degree }\end{array}$ & 98 & $26(26.5)$ & $1.00(0.51-1.95)$ & 0.99 & - & - \\
\hline
\end{tabular}


Table 4: Results of binary logistic regression for glycaemic control $(\mathrm{HbA1c}>=8)$ as dependent variable) for 562 of 629 eligible patients with an HbA1c value recorded

\begin{tabular}{|c|c|c|c|c|c|c|}
\hline & Total & $\begin{array}{l}\text { No }(\%) \\
\text { HbA1c } \\
>=8\end{array}$ & $\begin{array}{l}\text { Unadjusted odds } \\
\text { ratio }(95 \% \mathrm{CI})\end{array}$ & $\begin{array}{l}\mathrm{P} \\
\text { value }\end{array}$ & $\begin{array}{l}\text { Adjusted odds } \\
\text { ratio }(95 \% \mathrm{CI})\end{array}$ & $\begin{array}{l}\mathrm{P} \\
\text { value }\end{array}$ \\
\hline \multicolumn{7}{|l|}{ Sex } \\
\hline Males & 315 & $105(33.3)$ & 1.00 & & - & - \\
\hline Females & 247 & $78(31.6)$ & $0.92(0.65-1.32)$ & 0.66 & - & - \\
\hline \multicolumn{7}{|l|}{ Age } \\
\hline$<50$ & 79 & $36(45.6)$ & 1.00 & & 1.00 & \\
\hline $50-59$ & 131 & $55(42.0)$ & $0.86(0.49-1.52)$ & 0.61 & $1.02(0.55-1.92)$ & 0.95 \\
\hline $60-69$ & 216 & $61(28.2)$ & $0.47(0.28-0.80)$ & 0.01 & $0.50(0.28-0.91)$ & 0.02 \\
\hline$>70$ & 135 & $31(23.0)$ & $0.35(0.19-0.64)$ & 0.00 & $0.31(0.16-0.59)$ & 0.00 \\
\hline \multicolumn{7}{|l|}{ SIMD } \\
\hline $\begin{array}{l}1 \text { (most } \\
\text { deprived) }\end{array}$ & 70 & $26(37.1)$ & 1.00 & & - & - \\
\hline 2 & 100 & $34(34.0)$ & $0.87(0.46-1.65)$ & 0.67 & - & - \\
\hline 3 & 111 & $38(34.2)$ & $0.88(0.47-1.64)$ & 0.69 & - & - \\
\hline 4 & 171 & $56(32.7)$ & $0.82(0.46-1.47)$ & 0.51 & - & - \\
\hline $\begin{array}{l}5 \text { (least } \\
\text { deprived) }\end{array}$ & 94 & $27(28.7)$ & $0.68(0.35-1.32)$ & 0.26 & - & \\
\hline \multicolumn{7}{|c|}{ Diabetes Duration } \\
\hline$<2$ years & 66 & $23(34.8)$ & 1.00 & & - & - \\
\hline $2-5$ years & 162 & $45(27.8)$ & $0.72(0.39-1.33)$ & 0.29 & - & - \\
\hline $6-9$ years & 180 & $63(35.0)$ & $1.01(0.56-1.82)$ & 0.98 & - & - \\
\hline$>10$ years & 154 & $52(33.8)$ & $0.95(0.52-1.75)$ & 0.88 & - & - \\
\hline \multicolumn{7}{|l|}{ Treatment } \\
\hline Metformin & 166 & $\begin{array}{l}22 \\
(13.3 \%)\end{array}$ & 1.00 & & 1.00 & \\
\hline Sulph & 48 & $\begin{array}{l}11 \\
(22.9 \%)\end{array}$ & $1.95(0.87-4.37)$ & 0.11 & $2.57(1.10-6.00)$ & 0.03 \\
\hline Met / sulph & 247 & $\begin{array}{l}106 \\
(42.9 \%)\end{array}$ & $4.92(2.94-8.23)$ & $<0.01$ & $5.95(3.47-10.20)$ & $\begin{array}{l}<0.0 \\
1\end{array}$ \\
\hline Injections of & 61 & $\begin{array}{l}38 \\
(62.3 \%)\end{array}$ & $10.81(5.45-21.46)$ & $<0.01$ & $10.27(5.03-2.94)$ & $\begin{array}{l}<0.0 \\
1\end{array}$ \\
\hline $\begin{array}{l}\text { Diet/lifestyle } \\
\text { Frequency }\end{array}$ & 37 & $5(13.5 \%)$ & $1.03(0.36-2.91)$ & 0.97 & $1.04(0.36-3.00)$ & 0.95 \\
\hline No strips & 136 & $\begin{array}{l}40 \\
(29.4 \%)\end{array}$ & 1.00 & & 1.00 & \\
\hline $\begin{array}{l}<\text { Once per } \\
\text { week }\end{array}$ & 55 & $\begin{array}{l}17 \\
(30.9 \%)\end{array}$ & $1.07(0.54-2.12)$ & 0.84 & $0.96(0.45-2.06)$ & 0.93 \\
\hline $\begin{array}{l}1-4 \text { times per } \\
\text { week }\end{array}$ & 202 & $\begin{array}{l}63 \\
(31.2 \%)\end{array}$ & $1.09(0.68-1.75)$ & 0.73 & $0.91(0.54-1.54)$ & 0.73 \\
\hline $\begin{array}{l}4-7 \text { times per } \\
\text { week }\end{array}$ & 77 & $\begin{array}{l}22 \\
(28.6 \%)\end{array}$ & $0.96(0.52-1.78)$ & 0.90 & $0.66(0.34-1.31)$ & 0.24 \\
\hline
\end{tabular}




\begin{tabular}{lllllll}
\hline At least daily & 92 & $\begin{array}{l}41 \\
(44.6 \%)\end{array}$ & $1.93(1.11-3.35)$ & 0.02 & $1.24(0.67-2.31)$ & 0.50
\end{tabular}
$(44.6 \%)$ 